\title{
Online processing of tone and intonation in Mandarin: Evidence from ERPs
}

\author{
Min Liu*, Yiya Chen, Niels O. Schiller \\ Leiden University Center for Linguistics, Leiden Institute for Brain and Cognition, Leiden University, The Netherlands
}

\section{A R T I C L E I N F O}

\section{Article history:}

Received 3 February 2016

Received in revised form

22 August 2016

Accepted 23 August 2016

Available online 24 August 2016

Keywords:

Tone2

Tone4

Intonation

Mandarin

Attentive processing

P300

\begin{abstract}
A B S T R A C T
Event-related potentials (ERPs) were used to investigate the online processing of tone and intonation in Mandarin at the attentive stage. We examined the behavioral and electrophysiological responses of native Mandarin listeners to Mandarin sentences, which contrast in final tones (rising Tone 2 or falling Tone4) and intonations (Question or Statement). A clear P300 effect was observed for question-statement contrast in sentences ending with Tone4, but no ERP effect was found for question-statement contrast in sentences ending with Tone2. Our results provide ERP evidence for the interaction of tone and intonation in Mandarin, confirming the findings with behavioral metalinguistic data that native Mandarin listeners can distinguish between question intonation and statement intonation when the intonation is associated with a final Tone4, but fail to do so when the intonation is associated with a final Tone2. Our study extended the understanding of online processing of tone and intonation (1) from the pre-attentive stage to the attentive stage and (2) within a larger domain (i.e. multi-word utterances) than a single word utterance.
\end{abstract}

(c) 2016 Elsevier Ltd. All rights reserved.

\section{Introduction}

In spoken language processing, different aspects of linguistic information are involved, such as lexical, semantic, syntactic and prosodic information (Friederici, 2002; Isel et al., 2005). Among these aspects, prosodic information, especially pitch information, has been shown to be indispensible for spoken language processing in tonal languages such as Mandarin (e.g., Li et al., 2011). Tone and intonation have been considered the two most significant prosodic features of Mandarin speech (Tseng and Su, 2014). At the lexical level, F0 is employed to differentiate the four lexical tones (Tone1 - high-level, Tone2 - mid-rising, Tone3 - low-dipping and Tone4 - high-falling), which contrast lexical meanings (Cutler and Chen, 1997; Yip, 2002). At the sentential level, F0 is also used to convey post-lexical information, for example, intonation types (e.g., question intonation, statement intonation) (Ladd, 2008). Although other acoustic correlates (such as duration, intensity and phonation) have also been shown to contribute to cue tonal and intonational contrasts (Garellek et al., 2013; Hu, 1987; Shi, 1980; Xu, 2009; Yu and Lam, 2014), F0 has been identified as the primary acoustic correlate of both tone and intonation in Mandarin (Ho, 1977; Shen, 1985; Wu, 1982; Xu and Wang, 2001; Xu, 2004). It may therefore not be surprising that tone and intonation interact with

\footnotetext{
* Correspondence to: Leiden University Center for Linguistics, Postbus 9515, 2300 RA Leiden, The Netherlands.

E-mail address: m.liu@hum.leidenuniv.nl (M. Liu).
}

each other both in production and perception.

The interaction of tone and intonation in Mandarin has aroused great interests among researchers, and several models or theories have been put forward based mainly on acoustic data since the first studies on the topic by Chao (Chao, 1929, 1933). Of these acoustic studies, a general belief is that question intonation has higher F0 than statement intonation (Cao, 2004; Gårding, 1987; Shen, 1989; Wu, 1996). However, there is controversy about the temporal scope of such higher FO in question intonation. Two alternative views have been established. One holds that there is an overall F0 rising of sentences in questions compared to statements (Ho, 1977; Shen, 1989; Yuan, 2011). The other claims that the F0 difference between questions and statements is more pronounced towards the end of the sentences (Kratochvil, 1998; Liu and Xu, 2005; Xu, 2005; Peng et al., 2005).

Different from the above acoustic studies, Liang and Van Heuven (2007) conducted intonation perception experiments with a seven-syllable-sentence containing merely high-level tone syllables. They manipulated both the overall pitch level of the sentence and the pitch level of the final tone. Results showed that manipulating the final rise has a much stronger effect on the perception of intonation type than manipulation of the overall pitch level, indicating that the $\mathrm{FO}$ of the final tone is more important than that of the whole sentence for intonation perception.

Not unique to Mandarin, the final rise has been shown to be a language-universal perceptual cue for question intonation (Gussenhoven and Chen, 2000). In a made-up language, Gussenhoven and Chen (2000) tested the perceptual cues for question 
intonation across three different language groups. All listeners tended to take the higher peak, the later peak and the higher end rise as cues for question intonation perception. In Cantonese, another representative language other than Mandarin within the Sinitic language family, Ma et al. (2011) also found that the perception of questions and statements relies primarily on the F0 characteristics of the final syllables.

Apart from studies on the temporal domain of perceptual cues of intonation, there has also been research, though regretfully little, on the effect of intonation on tone perception and vice versa. Connell et al. (1983) ran a tone perception experiment in Mandarin and found that intonation-induced F0 has little effect on tone perception. Tone identity maintains in question intonation. With regard to the effect of tone on intonation perception, Yuan (2011) found that in Mandarin, questions ending with Tone4 (falling tone) were easier to identify than questions ending with Tone2 (rising tone). Three mechanisms were proposed for question intonation: an overall higher phrase curve, higher strengths of sentence-final tones and a tone-dependent mechanism. The tonedependent mechanism conflicts with the strength mechanism on the final Tone2, possibly accounting for the difficulty of question identification in sentences ending with Tone2. In sentences ending with Tone4, the tone-dependent mechanism flattens the falling slope of the final falling, making question intonation perceptually more salient for falling tone (Yuan, 2006).

Unlike in Mandarin, the intonation-induced F0 affects tone perception in Cantonese. Low tones $(21,23,22)$ (tone values in 5 -point scale notation, each tone is described by the initial and the end point of the pitch level) were misperceived as the mid-rising tone (25) at the final positions of questions (Fok-Chan, 1974; Kung et al., 2014; Ma et al., 2011). This is probably because with a rising tail superimposed on all tone contours by question intonation (Ma et al., 2006), the F0 contour of the low tones in questions resembles that of a mid-rising tone in questions. As for the effect of tone on intonation perception, native listeners were least accurate of all the six tones in Cantonese in distinguishing statements and questions for sentences ending with Tone 25 (Ma et al., 2011), suggesting that listeners confused the rising contour of Tone 25 with the final rise of question intonation.

Taken together, potential conflicts exist between tone and intonation in Mandarin and Cantonese, causing processing difficulties at the behavioral level. However, the underlying neural mechanisms leading to the eventual behavioral decisions are not yet clear. To shed light on this issue, research is needed to investigate the online processing of tone and intonation.

In recent years, a number of neurophysiological studies in regard to pitch processing have emerged, mainly with lesion, dichotic listening and functional neuroimaging techniques (Gandour et al., 1992; Klein et al., 2001; Van Lancker and Fromkin, 1973; Wang et al., 2003). However, due to the low temporal resolution of these techniques, event-related potentials (ERPs), a high temporal resolution measure was introduced to pitch processing, offering more precise temporal information of online processing.

The majority of ERP studies relevant to pitch processing focus on the neural mechanisms of tone processing at the pre-attentive stage, where participants are directed to watch a silent movie or read a book and to ignore the auditory input (Fritz et al., 2007). In these studies, the ERP component of interest is the MismatchNegativity (MMN), an indicator of acoustic change detection (Näätänen, 2001; Pulvermüller and Shtyrov, 2006). Only two studies examined the online processing of both tone and intonation in Mandarin, to our knowledge. Ren et al., (2009) constructed an oddball sequence. A word with lexical Tone4 (i.e., /gai4/1 ), uttered

\footnotetext{
${ }^{1}$ The number following the letters in Mandarin Pinyin represents Mandarin
}

with statement intonation was presented as the standard stimulus, and /gai4/ with question intonation was presented as the deviant stimulus to native Mandarin listeners. Their results showed a clear MMN effect when subtracting the waveform of the standard from that of the deviant. In another study, Ren et al. (2013) adopted a three-stimuli oddball paradigm. The standard stimulus was /lai2/ with statement intonation. The deviant stimuli included an intonation deviant (/lai2/ with question intonation) and a lexical tone deviant (/lai4/ with statement intonation). Results showed an MMN for the tone deviant but not for the intonation deviant. As the MMN is linked to higher order perceptual processes underlying stimulus discrimination (Pulvermüller and Shtyrov, 2006), the above two studies suggest that at the pre-attentive stage, native listeners can tease apart question intonation from statement intonation when the intonation is combined with Tone4, but they are not able to tease apart the two types of intonation when the intonation is combined with Tone2, just as what Yuan (2011) has reported with behavioral perceptual judgment data. This correspondence of the online MMN results with the offline behavioral results validates the initial ERP evidence of the interaction of tone and intonation in Mandarin.

In addition to Mandarin, ERP evidence of online interplay of tone and intonation is also revealed in Cantonese (Kung et al., 2014). In this study, Cantonese participants were asked to perform a lexical-identification task, i.e., choosing the right word they heard from six Cantonese words on the screen in the form of Chinese characters, and the six words were tonal sextuplets of the critical word. ERP analyses revealed a P600 effect for low tone in questions relative to low tone in statements. The P600 effect was explained as an indicator of reanalysis, in the presence of a strong conflict of two competing representations activated in questions ending with low tones. The two representations are a lexical representation with a low tone on the one hand and a lexical representation with a high rising tone on the other. Special attention should be paid to the fact that Kung et al. (2014) found a P600 effect in the semantically neutral sentence context. In their subsequent study, when introducing a highly constraining semantic context to the target words, the P600 disappeared, suggesting that semantic context plays a role in resolving the online conflict between intonation and tone.

Several remaining issues may be noticed given the above ERP studies on the processing of tone and intonation. First, the MMN studies of Mandarin restricted their attention to the interaction of

Table 1

An example of the experiment design.

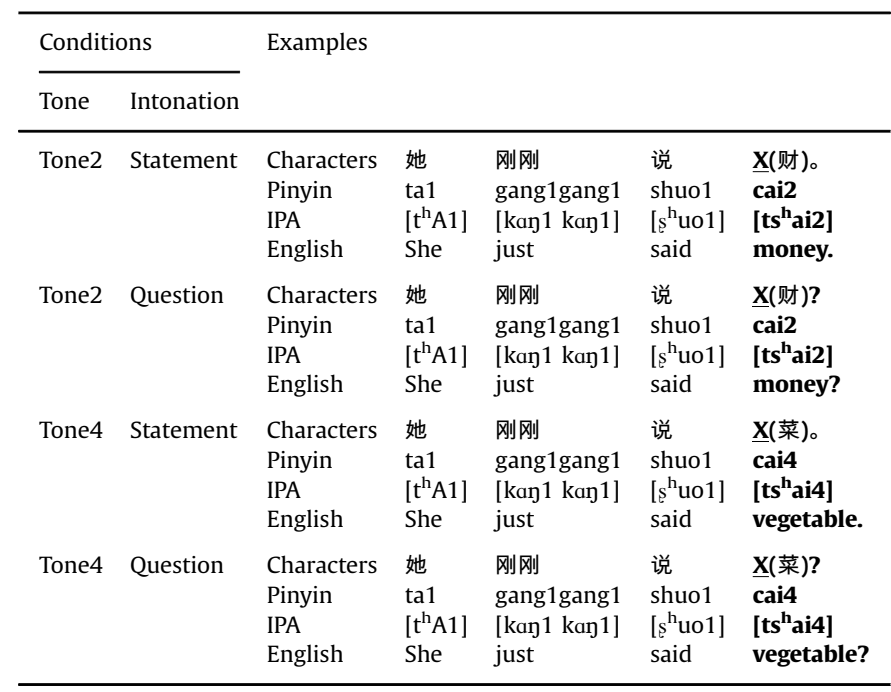

Note. The critical syllables are in bold. 


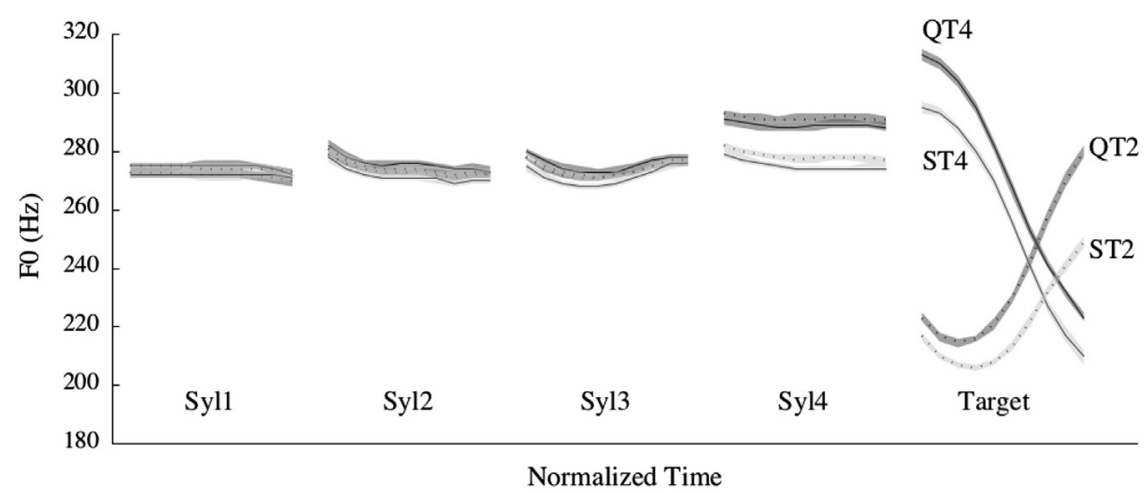

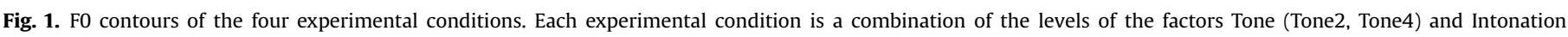

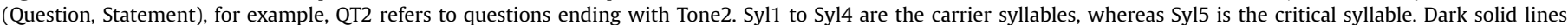

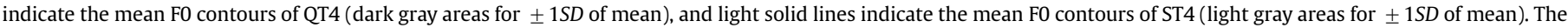
corresponding dark dotted lines and light dotted lines indicate the mean F0 contours of QT2 and ST2, respectively.

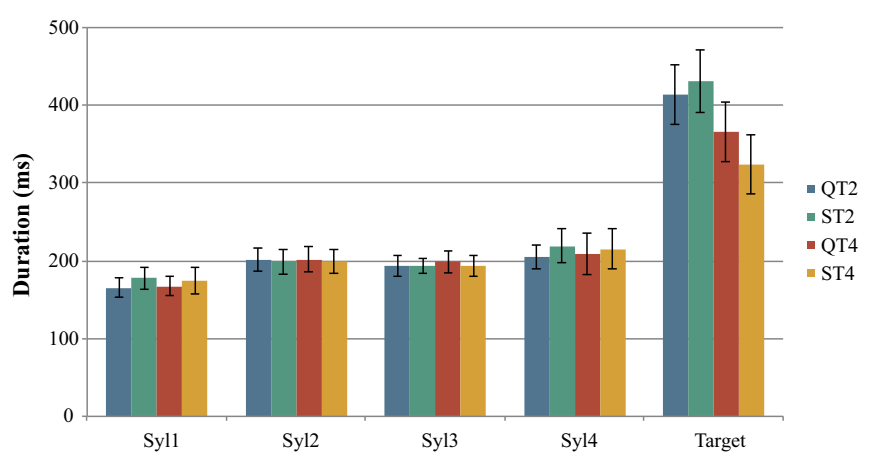

Fig. 2. Duration means $\pm 1 S D$ for each syllable of the four experimental conditions.

tone and intonation in a one-syllable-sentence domain. Given that intonation is a feature at the sentential level that typically spans over several lexical items, it would be not only interesting but also necessary to investigate how tone and intonation information are processed when the length of an utterance is extended from one syllable to several syllables. Specifically, the question that arises here is whether native Mandarin listeners can disentangle intonation information from tone information over a broader sentence domain. Second, the extant ERP studies (Ren et al., 2009, 2013) investigated tone and intonation processing at the pre-attentive stage where the attention of the participants was directed to elsewhere. In this kind of design, there is no way to measure the behavioral effects of the deviant acoustic stimulus in the stream, making it impossible to distinguish between automatic neural responses arising from acoustic variability and responses related to "attention capture" (Fritz et al., 2007). Therefore, the present study aims to extend the online processing of tone and intonation from the pre-attentive stage to the attentive processing stage. Moreover, we are interested in whether the processing of tone and intonation at the attentive stage differs from that at the pre-attentive stage. Third, the ERP study on Cantonese (Kung et al., 2014) extended the online processing of tone and intonation to a broader sentence domain. However, this study employed a lexical identification task rather than a pitch identification task per se. In this way, a potential concern is that the interaction of tone and intonation is not directly examined. Also, as stated earlier, intonation

(footnote continued)

tone. " 1 " is Tone1 (high-level tone); " 2 " is Tone2 (mid-rising tone); "3" is Tone3 (lowdipping tone), and "4" is Tone4 (high-falling tone).
Table 2

Acoustic properties of the experiment materials ( $S D$ s in parentheses).

\begin{tabular}{llllll}
\hline Parameters & Syllable & $\begin{array}{l}\text { Tone2, } \\
\text { Statement }\end{array}$ & $\begin{array}{l}\text { Tone2, } \\
\text { Question }\end{array}$ & $\begin{array}{l}\text { Tone4, } \\
\text { Statement }\end{array}$ & $\begin{array}{l}\text { Tone4, } \\
\text { Question }\end{array}$ \\
\hline Duration (ms) & Syl1 & $178(15)$ & $165(13)$ & $174(17)$ & $167(12)$ \\
& Syl2 & $199(16)$ & $201(15)$ & $199(16)$ & $202(16)$ \\
& Syl3 & $194(10)$ & $194(14)$ & $193(13)$ & $199(14)$ \\
& Syl4 & $219(21)$ & $204(15)$ & $215(26)$ & $209(26)$ \\
& Syl5 & $430(40)$ & $414(39)$ & $324(38)$ & $366(38)$ \\
Mean F0 (Hz) & Syl1 & $274(11)$ & $272(10)$ & $272(9)$ & $275(8)$ \\
& Syl2 & $274(9)$ & $274(8)$ & $272(7)$ & $276(8)$ \\
& Syl3 & $274(8)$ & $274(7)$ & $272(8)$ & $276(8)$ \\
& Syl4 & $278(7)$ & $292(9)$ & $275(8)$ & $289(9)$ \\
Max F0 (Hz) & Syl5 & $250(12)$ & $280(14)$ & $296(10)$ & $313(13)$ \\
Min F0 (Hz) & Syl5 & $205(6)$ & $214(8)$ & $210(16)$ & $223(11)$ \\
F0 range (Hz) & Syl5 & $45(10)$ & $66(12)$ & $86(20)$ & $90(11)$ \\
\hline
\end{tabular}

distorts tone identity in Cantonese but not in Mandarin. There arises the question of whether the mechanism underlying tone and intonation processing in Mandarin is different from that in Cantonese. Fourth, semantic context affects the processing of tone and intonation in Cantonese. It has also been proven that in Mandarin a constraining semantic context facilitates the processing of tone (Ye and Connine, 1999) and intonation (Liu et al., 2016). In this study, we therefore took semantic context as a control variable and set it to be neutral so that it can serve as a baseline comparison for further research. In short, the present study was designed to investigate the online processing of tone and intonation in Mandarin over a broader sentence domain at the attentive stage under neutral semantic context.

The ERP component that is of our particular interest in the present study is the P300 (the P3b in particular). The P300 is a positive-going deflection peaking at around $300 \mathrm{~ms}$ in a time window of about $250-500 \mathrm{~ms}$, or even to $900 \mathrm{~ms}$ (Patel and Azzam, 2005). It is thought to be elicited in the process of decision making (Hillyard et al., 1973; Nieuwenhuis et al., 2005; Rohrbaugh et al., 1974; Smith et al., 1970; Verleger et al., 2005), reflective of processes involved in stimulus evaluation or categorization (Azizian et al., 2006; Frenck-Mestre et al., 2005; Johnson and Donchin, 1980; Kutas et al., 1977).

In the present study, we examined participants' behavioral and electrophysiological responses to Mandarin sentences contrasting in final tones (Tone2 or Tone4) and intonations (Question or Statement). We employed two pitch identification tasks. Participants were asked to categorize the final tone or intonation of the stimuli. A two-alternative forced choice (2AFC) task was adopted 
in this study. 2AFC is considered a highly simplified decision making condition, in which a choice must be made between two responses based on limited information about which is correct (Bogacz et al., 2006). It best captures the essence of decisionmaking, and therefore, fits for the purpose of eliciting P300. To decrease fast guesses in the task, a $0.5 / 0.5$ probability of each category was implemented, as in Pfefferbaum et al., (1983). The same 2AFC task was performed on all the stimuli, not just on one specific category to avoid selective tuning, which has been proved to be unnecessary and insufficient for P300 enhancement (Hillyard et al., 1973; Rohrbaugh et al., 1974).

We hypothesized that under neutral semantic context, at the attentive stage, native Mandarin listeners should be able to disentangle question intonation from statement intonation when the intonation concurs with a final Tone4. Behaviorally, this should be reflected in high identification accuracy. Electrophysiologically, we expect a P300 effect for questions ending with Tone4 relative to statements ending with Tone4. In the case of Tone2, due to the difficulty in teasing apart intonation information from tone information for participants, the behavioral performance is expected to show a lower accuracy. No clear P300 is expected between questions ending with Tone 2 and statements ending with Tone2.

\section{Method}

\subsection{Participants}

Twenty right-handed native speakers of Mandarin from Northern China were paid to participate in the experiment. They were undergraduate or graduate students at Renmin University. Five of the participants were excluded from the analysis because of excessive artifacts in their EEG data. Age of the remaining 15 participants ( 7 male, 8 female) ranged from 20 to $28(M \pm S D$ : $23.8 \pm 2.8$ ). None of them had received any formal musical training or had reported any speech or hearing disorders. Informed consent was obtained from all the participants before the experiment.

\subsection{Materials}

Forty monosyllabic minimal word pairs varying by tone (Tone2 or Tone4) with otherwise identical segments were selected. Each minimal Tone2_Tone4 word pair contains words of comparable word frequency, phonological neighborhood density, and syntactic word category. To avoid any word frequency effect, only frequent words with more than 4500 occurrences in a corpus of 193 million words were used ( $\mathrm{Da}, 2004)$. Phonological neighborhood density, in the present study, was defined as the number of homophones, which share exactly the same pronunciation both in segments and lexical tones (following Chen et al., 2009). Tone 2 words have similar phonological neighborhood densities as their Tone4 equivalents. The forty word pairs comprise mainly pairs of nouns ( 32 pairs), but pairs of verbs ( 6 pairs) and adjectives ( 2 pairs) were also included to guarantee sufficient number of stimuli.

All the critical words were embedded in the final position of a five-syllable carrier sentence, i.e., ta1 gang1gang1 shuo1 X (English: She just said X), produced with either a statement or a question intonation. Only high-level tones (Tone1) were contained in the carrier sentence. This is to avoid downstep effect and to minimize the contribution of tone to the observed F0 movement (Shih, 2000). The carrier sentence was semantically meaningful but offered neutral semantic context to the target stimuli. By using the semantically neutral carrier, intonation information was successfully elicited. On the other hand, potential confound of semantic context with sentence prosody was excluded (Kung et al., 2014).

In total, 160 target sentences (40 Syllables $\times 2$ Tones $\times 2$
Intonations) were designed (see Table 1 for an example). Moreover, another 240 filler sentences were constructed. They resembled the target sentences in carrier sentence structure but differed from them in critical syllables in terms of either segmental composition or lexical tone (e.g. Tone1/Tone3). Pooling target sentences and filler sentences resulted in 400 sentences, which were uttered for the perception experiment.

\subsection{Recording and stimuli preparation}

One female native speaker of Mandarin, who was born and raised in Beijing, recorded the sentences. The recordings took place in a soundproof recording booth at the Phonetic Lab of Leiden University. Sentences were randomly presented to the speaker and recorded at 16-bit resolution and a sampling rate of $44.1 \mathrm{kHz}$. To eliminate paralinguistic information, the speaker was instructed to avoid any exaggerated emotional prosody during the recording.

This female speaker's recordings were chosen for the experiment for the clarity and consistency of the articulation. More importantly, the acoustic results of her recordings (see Figs. 1 and 2) showed comparable F0 realization of tone and intonation to a prior study (Yuan, 2006) and were therefore taken as the prototypical patterns for the perception study. In the subsequent perception experiment, the amplitude of all the sentences was normalized in PRAAT (Boersma and Weenink, 2015).

The acoustic results (see Table 2) of the speech files showed that over our target stimuli pairs (which are five syllables long), the F0 and duration of the first three syllables revealed no differences between the two types of intonation for sentences ending with both Tone 2 and Tone4 (all ps > 0.05). However, intonation affected the fourth syllable with a significantly raised Fo for the level tone over a question in comparison with that over a statement in both the Tone2 $(t(39)=7.22, p<0.001$, Cohen's $d=1.64)$ and the Tone $4(t(39)=7.17, p<0.001$, Cohen's $d=1.64)$ conditions. When it comes to the critical syllable (i.e. the fifth syllable of the utterance), question with a final Tone2 had a significantly wider F0 range than its statement counterpart $(t(39)=9.87, p<0.001$, Cohen's $d=1.90)$. The minimum F0 showed a slight increase $(t(39)=$ 6.37, $p<0.001$, Cohen's $d=1.27$ ), while a sharp rise of the maximum F0 was observed in the question condition relative to the statement condition $(t(39)=11.47, p<0.001$, Cohen's $d=2.30$ ), suggesting a trend of sharper final rising. For questions with a final Tone4, there was an overall higher F0 contour than statements with a final Tone4. Though the F0 range was comparable between the two conditions $(t(39)=1.24, p=0.22$, Cohen's $d=0.30)$, the initial F0 $(t(39)=8.65, p<0.001$, Cohen's $d=1.40)$ and the final F0 $(t(39)=4.48, p<0.001$, Cohen's $d=0.80)$ of the high-falling tone were significantly higher in the question intonation (both ps < 0.001). Consistent with previous findings (Cao, 2004; Wu, 1996), our data showed that the pitch contour of Tone 2 and Tone 4 maintained in both question and statement intonations, but pitch height differs between the two intonations across final tone identities. In addition to F0, duration also played a role in making a distinction between question intonation and statement intonation. Consistent with Yuan (2006), final Tone4 syllables in question intonation had significantly longer duration than those in statement intonation $(t(39)=6.73, p<0.001$, Cohen's $d=1.11)$. However, final Tone2 syllables tended to be slightly shorter in question intonation than in statement intonation $(t(39)=-3.10, p<0.01$, Cohen's $d=-0.41$ ), whereas similar duration was found between the two intonation types for final Tone2 syllables in Yuan (2006). Considering the temporal scope of the interaction of tone and intonation, our data lend no support to the global nor to the strictly local theory of question intonation, but are sympathetic towards the final-rising theory given that F0 did not start to 
increase significantly until the pre-final syllable.

\subsection{Task}

Participants were asked to perform two pitch identification tasks. The tone identification task consisted of half of the trials (1 sentence in a trial, 400 sentences in total), whereas the intonation identification task consisted of the other half. The specific task was randomly allocated from trial to trial. Task types were indicated by tone and intonation marks in Mandarin Pinyin system. When "^" marks ("” stands for Tone2; "” stands for Tone4) appeared on the screen, participants were asked to identify the final tone of the sentence they heard. When "。?" marks appeared ("。" stands for statement intonation; "?" stands for question intonation), they were asked to identify whether the previously presented sentence bears a statement intonation or a question intonation. To complete the tasks, participants were requested to press the corresponding button within a two-second time limit. The tone and intonation marks used here are acquired at a very early age by Mandarin native speakers. No participants had reported difficulty in understanding the tasks.

\subsection{Procedure}

Participants were tested individually in a soundproof booth. Stimuli were randomly presented using E-Prime 2.0 software through loudspeakers at a comfortable listening level of a $75 \mathrm{~dB}$ sound pressure level at source. Instructions were given to participants visually on screen and orally by the experimenter in Mandarin before the experiment.

The whole experiment included one practice session and four experiment sessions. The practice session contained 12 trials. Each experiment session encompassed 100 trials. Between each session, there was a 3-min break. An experiment trial started with a $100 \mathrm{~ms}$ warning beep, followed by a $300 \mathrm{~ms}$ pause. After that an auditory sentence was presented while a red fixation cross appeared on the screen. Participants were instructed to gaze on the fixation cross and not to blink or move during the presentation of the sentence. In the meantime, participants were instructed to pay special attention to the final tone and the intonation of the sentence. One second after the offset of the stimuli, they were asked to perform either a tone identification task or an intonation identification task as accurately as possible within a two-second time limit. By doing so, the ERP effects of interest can be prevented from being confounded by motor-related processes (Kung et al., 2014; Salisbury et al., 2001). The Inter Stimulus Interval (ISI) was $500 \mathrm{~ms}$.

\subsection{EEG data recording}

EEG was recorded from $64 \mathrm{Ag} / \mathrm{AgCl}$ electrodes mounted in an elastic cap (Neuroscan system) with a sampling rate of $500 \mathrm{~Hz}$. The right mastoid served as the reference electrode and $\mathrm{AFz}$ as the ground. Electrooculograms (EOGs) were monitored vertically and horizontally. Vertical EOGs were recorded by electrodes placed above and below the left eye, while horizontal EOGs were recorded by electrodes placed at the outer canthi of the left and right eye. The impedance of all electrodes was kept below $5 \mathrm{~K} \Omega$.

\subsection{Behavioral data analysis}

Given that the behavioral responses were performed one second after the presentation of the stimuli, these delayed reaction time measurements were not further analyzed. Only Identification Rate (IR) was analyzed. IR was defined as the percentage of correct identification of tone in the tone identification task, and as the percentage of correct identification of intonation in the intonation identification task.

Statistical analyses were carried out with the package lme4 (Bates et al., 2015) in R version 3.1.2 (R Core Team, 2015). Binomial logistic regression models were constructed for the dependent variable Response (Correct or Incorrect) with Task, Tone, Intonation and their interactions as fixed factors, and Subjects and Items as random factors. The fixed factors were added in a stepwise fashion and their effects on model fits were evaluated via model comparisons based on log-likelihood ratios. To capture the binary nature of the dependent variable, a logistic link function was applied. The estimate $(\beta), \mathrm{z}$ and $p$-values are reported.

\subsection{EEG data analysis}

The EEG data were analyzed with Brain Version Analyzer (Version 2.0). A $0.05-20 \mathrm{~Hz}$ band-pass filter was applied offline to the original EEG data. ERP epochs were defined in a $1200 \mathrm{~ms}$ interval from $-400 \mathrm{~ms}$ to $800 \mathrm{~ms}$ time-locked to the onset of the critical word. The baseline was calculated from $-400 \mathrm{~ms}$ to $-200 \mathrm{~ms}$. In our acoustic data, F0 differences among the experimental conditions have been observed from the pre-final syllable. We therefore defined the time interval before the pre-final syllable as the baseline. Epochs with excessive eye movements and blinks were discarded. The criteria for artifact rejection were a maximal sudden voltage change of $25 \mu \mathrm{V}$ in $100 \mathrm{~ms}$, a maximal amplitude difference of $100 \mu \mathrm{V}$ in a time window of $200 \mathrm{~ms}$ and a low amplitude activity within a range of $0.5 \mu \mathrm{V}$ in a time window of $100 \mathrm{~ms}$.

Prior to averaging, trials with incorrect behavioral responses were excluded. However, ERP data were collapsed across task types during averaging because on the one hand, the tone identification task evoked very few response errors, and on the other hand, we did not observe differences in the ERP waveforms between the tone identification task and the intonation identification task under each experimental condition. To gain more statistical power, we aggregated all the correctly identified artifact-free trials from the tone identification task and the intonation identification task in the ERP analyses. As a result, a total of $30 \%$ of the data points were rejected. We found a clear peak in only one of the experimental conditions. Thus, in the following, we will exclusively report mean amplitudes.

A set of 27 electrodes was used for analyses, including 3 midline electrodes (Fz, $\mathrm{Cz}$ and $\mathrm{Pz}$ ) and 24 lateral electrodes (F3/4, F1/2, FC3/4, FC1/2, C3/4, C1/2, CP3/4, CP1/2, P3/4, P1/2, PO5/6, PO3/4). The lateral electrodes were divided into six areas comprising four electrodes each (see Fig. 3). These six areas were Left Frontal (F3, F1, FC3, FC1), Right Frontal (F2, F4, FC2, FC4), Left Central (C3, C1, CP3, CP1), Right Central (C2, C4, CP2, CP4), Left Posterior (P3, P1, $\mathrm{PO}$, PO3) and Right Posterior (P2, P4, PO4, PO6). For each area, the mean amplitude of the four electrodes was calculated and used in the following analyses. Due to the different numbers of the midline electrodes and the lateral electrodes, we decided to run repeated measures ANOVAs on the midline electrodes and the lateral electrodes separately.

To establish the exact onset and range of the ERP effects, we ran repeated measures ANOVAs for 16 successive $50 \mathrm{~ms}$ time windows starting from the onset of the critical word up to $800 \mathrm{~ms}$ (following Schirmer et al., 2005). For the midline electrodes, withinsubject variables included Tone (Tone2, Tone4), Intonation (Question, Statement) and Region (Frontal, Central, Posterior). For the lateral electrodes, within-subject variables included Tone (Tone2, Tone4), Intonation (Question, Statement), Region (Frontal, Central, Posterior) and Hemisphere (Left, Right). Statistical significance was computed using the Greenhouse-Geisser correction when the assumption of sphericity was violated. Corrected $p$ - 


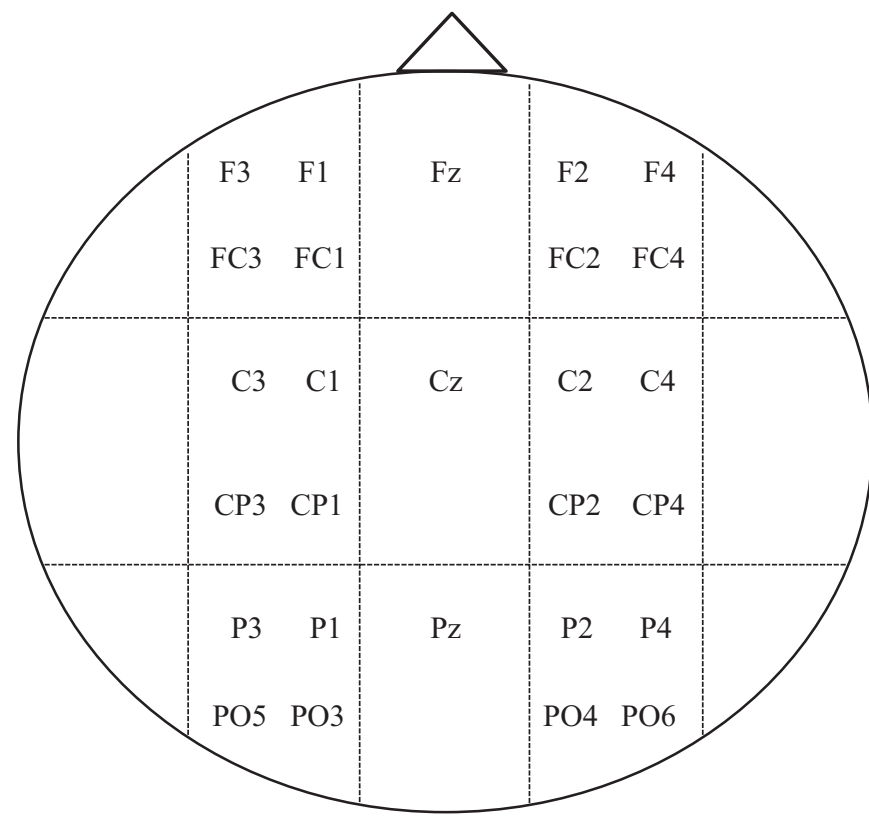

Fig. 3. Electrode areas used in the analyses. For the lateral electrodes, the amplitude of the four electrodes within each area was averaged.

values are reported.

\section{Results}

\subsection{Behavioral results}

Fig. 4 presents the identification rate of the four experimental conditions under different tasks. Tone stands for the tone identification task, and Intonation stands for the intonation identification task.

Results showed a significant main effect of Task $(\beta=0.69$, $\mathrm{z}=2.61, p<0.01)$ and Intonation $(\beta=1.99, \mathrm{z}=5.45, p<0.01)$ on the odds of correct responses over incorrect responses. Two-way interactions, i.e., Task $\times$ Tone, Task $\times$ Intonation, and Tone $\times$ Intonation, also reached significance (all $p s<0.01$ ). There was no threeway interaction of Task, Tone and Intonation $(p>0.1)$. Separate models for subset data of Tone and Intonation revealed that the effects of Task were manifested in that the tone identification task had much higher identification rate than the intonation identification task in questions ending with Tone 2 and Tone 4 , and also in statements ending with Tone2 (all $p s<0.05$ ). Due to the nearceiling level of identification performances in both tasks, no task difference was observed for statements ending with Tone4 $(p>0.05)$. Apparently, the tone identification task was much easier than the intonation identification task for the participants.

Separate models were also constructed for subset data of different tasks. For the tone identification task, a significant interaction of Tone $\times$ Intonation $(\beta=2.17, z=2.50, p<0.05)$ was found. Identification rate of Tone4 was lower than that of Tone2 in questions $(\beta=-1.54, \mathrm{z}=-2.95, p<0.01$ ), but no difference was found between the two in statements $(\beta=0.71, z=1.00, p>0.05)$. No intonation effect was found in either Tone2 or Tone4 sentence pairs (both $p s>0.05$ ). Overall, tone identification almost reached ceiling level across conditions. This suggests that the identity of tone was not hindered by intonation information.

With respect to the intonation identification task, a significant

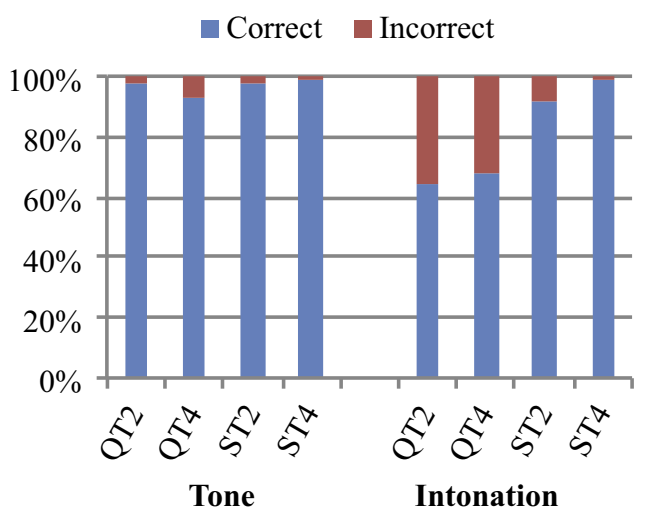

Fig. 4. Identification rate for each experimental condition under different tasks. Tone indicates the tone identification task; Intonation indicates the intonation identification task.

main effect of Intonation $(\beta=2.06, \mathrm{z}=5.14, p<0.01)$ and an interaction of Tone $\times$ Intonation were discovered $(\beta=2.61, z=2.95$, $p<0.01$ ). Question intonation had a much lower identification rate than statement intonation regardless of the final tone identities (both $p s<0.01$ ). Despite the fact that no difference was found for IR of question intonation between questions ending with Tone2 and questions ending with Tone $4(\beta=0.20, z=0.51, p>0.05)$, a higher identification rate of statement intonation was indeed discovered for statements ending with Tone4 relative to statements ending with Tone $2(\beta=2.68, z=3.61, p<0.01)$. This suggests that participants had more difficulties perceiving question intonation than statement intonation.

\subsection{ERP results}

Fig. 5 shows the grand average ERP waveforms time-locked to the onset of the critical syllables for 9 electrodes. Fig. 6 presents the topographic maps obtained in all the 64 electrodes. Since the focus of interest of this paper is tone and intonation effects, only tone-related and intonation-related effects and the corresponding interactions are discussed below.

A summary of the time-course analyses for the midline electrodes and the lateral electrodes are presented in Tables A1 and A2 (see Appendix A), respectively. Regions of Interest (ROIs) were identified as the time period when effects were consistently significant in two or more consecutive $50 \mathrm{~ms}$ time windows. Visual inspection of the waveforms also served as a complementary tool for the identification of ROIs. Consequently, we chose a ROI of 250 $400 \mathrm{~ms}$ for the midline electrodes. For the lateral electrodes, a larger time window of $250-450 \mathrm{~ms}$ was identified as the ROI.

The overall ANOVA for the mean amplitude of the midline electrodes in the time window of $250-400 \mathrm{~ms}$ revealed a main effect of Intonation $\left(F(1,14)=8.89, p<0.05, \eta_{\mathrm{p}}{ }^{2}=0.39\right)$, and a three-way interaction of Tone $\times$ Intonation $\times$ Region $(F(1.56$, $\left.21.79)=4.55, p<0.05, \eta_{\mathrm{p}}{ }^{2}=0.25\right)$. Follow-up ANOVAs were then performed for each level of Tone. Comparisons between QT2 and ST2 revealed neither a main effect of Intonation nor an interaction of Intonation $\times$ Region (both $p s>0.05$ ). However, the analysis comparing QT4 and ST4 yielded a significant main effect of Intonation $\left(F(1,14)=6.81, p<0.05, \eta_{\mathrm{p}}{ }^{2}=0.33\right)$ and a significant interaction of Intonation $\times$ Region $(F(1.85,25.83)=9.05, \mathrm{p}<0.01$, $\left.\eta_{\mathrm{p}}{ }^{2}=0.39\right)$. Separate ANOVAs for each level of Region revealed a significant main effect of Intonation at the central $(F(1,14)=6.55$, $\left.p<0.05, \eta_{\mathrm{p}}{ }^{2}=0.32\right)$ and posterior sites $(F(1,14)=13.49, p<0.01$, 
F3

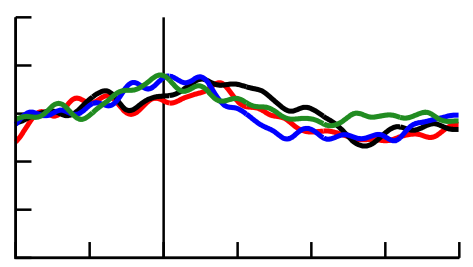

C3

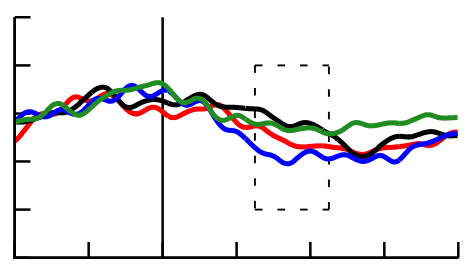

P3

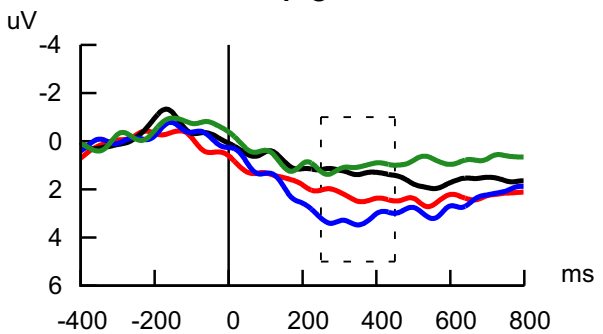

$\mathrm{Fz}$

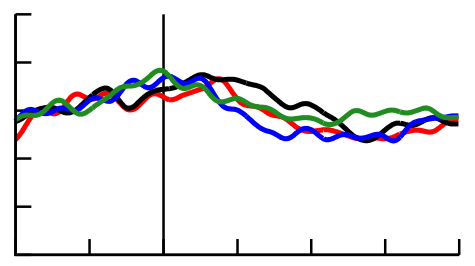

$\mathrm{Cz}$

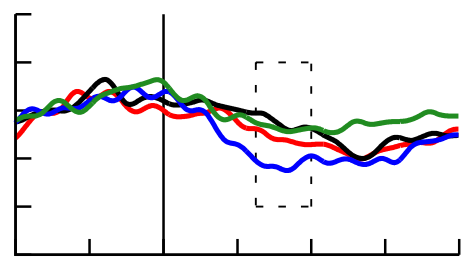

$\mathrm{Pz}$

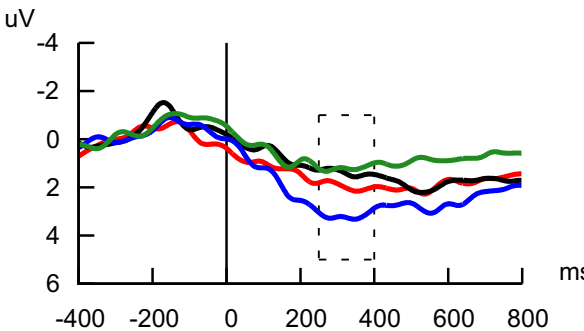

F4

QT2

QT4

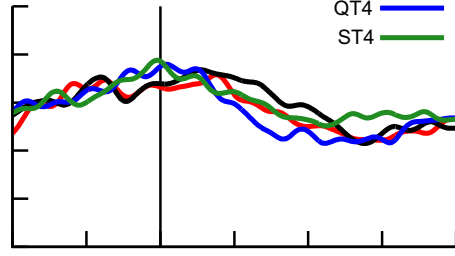

C4

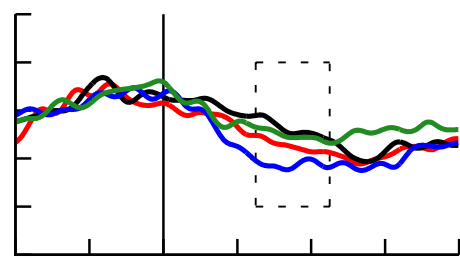

P4

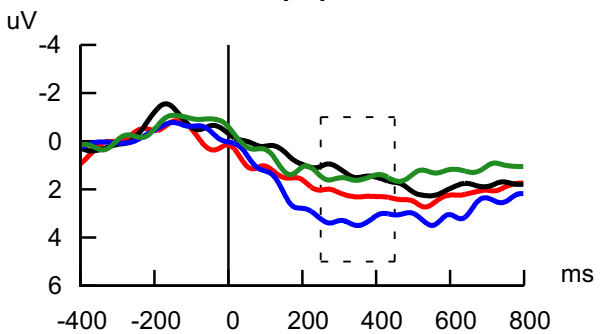

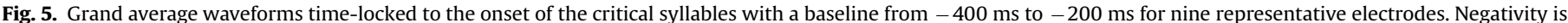
plotted upwards. The boxes with dash lines mark the P300 time-window for the questions ending with Tone 4 condition.

\section{Tone 2 conditions}

Question vs. Statement

$250-400 \mathrm{~ms}$

$250-450 \mathrm{~ms}$

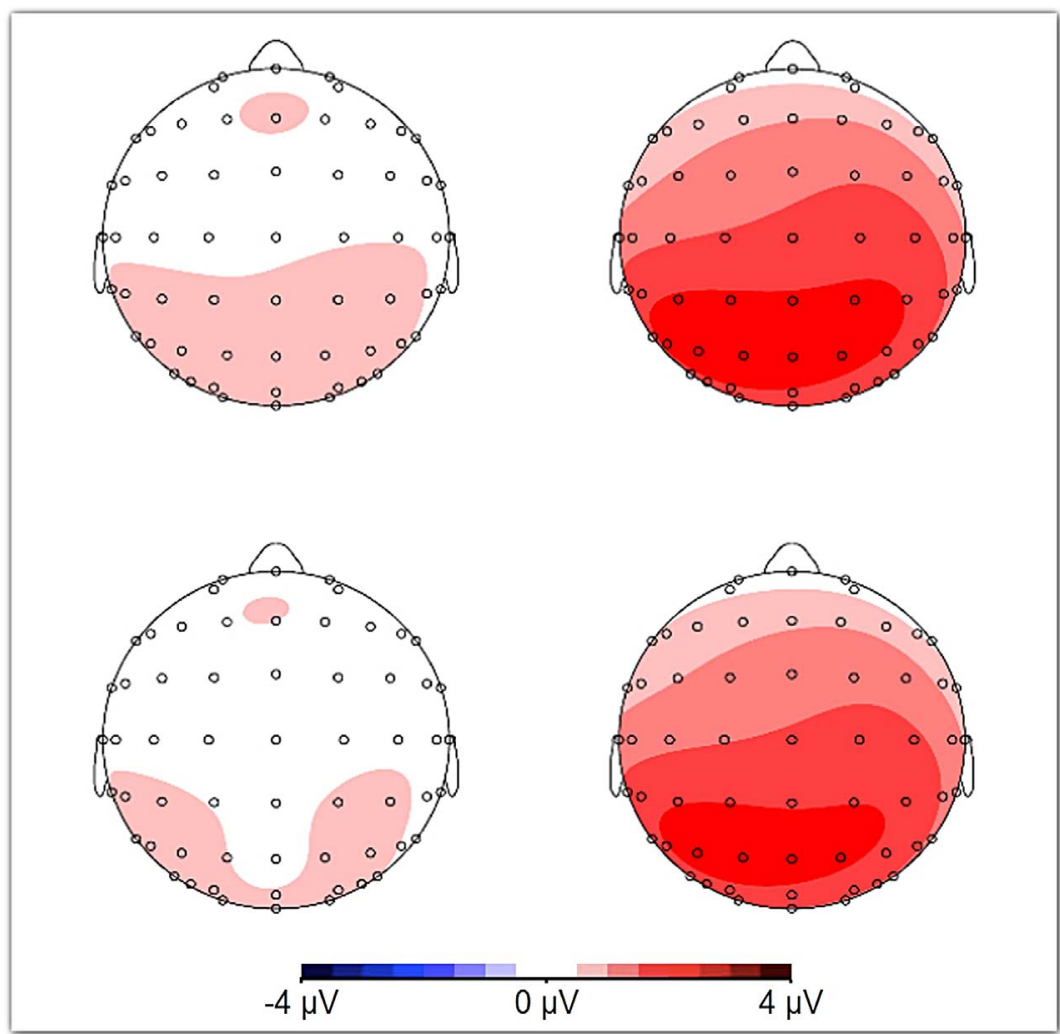

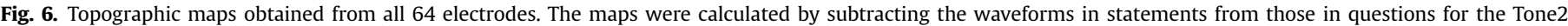

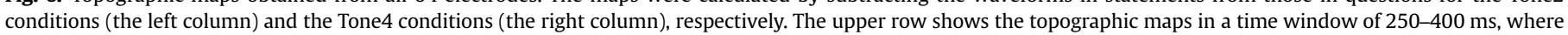

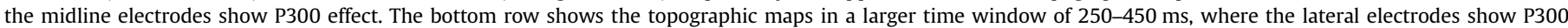
effect. 
$\eta_{\mathrm{p}}{ }^{2}=0.49$ ), with a larger positivity for QT4 than for ST4. No effect of Intonation was found at the frontal sites $(p>0.05)$.

As for the lateral electrodes, the overall ANOVA for the mean amplitude in the time window of $250-450 \mathrm{~ms}$ revealed a main effect of Intonation $\left(F(1,14)=10.18, p<0.01, \eta_{\mathrm{p}}{ }^{2}=0.42\right)$, a threeway interaction of Tone $\times$ Intonation $\times$ Region $(F(1.44,20.08)=$ 4.87, $p<0.05, \eta_{\mathrm{p}}{ }^{2}=0.26$ ), and also a three-way interaction of Intonation $\times$ Region $\times$ Hemisphere $(F(1.56,21.88)=3.84, p<0.05$, $\eta_{\mathrm{p}}{ }^{2}=0.22$ ). Follow-up ANOVAs for each level of Tone yielded no effects between QT2 and ST2 (all ps $>0.05$ ), but a significant main effect of Intonation $\left(F(1,14)=4.78, p<0.05, \eta_{\mathrm{p}}{ }^{2}=0.25\right)$, a significant two-way interaction of Intonation $\times$ Region $(F(1.95$, $\left.27.27)=12.08, p<0.01, \eta_{\mathrm{p}}{ }^{2}=0.46\right)$ and a significant three-way interaction of Intonation $\times$ Region $\times$ Hemisphere $(F(1.60,22.35)=$ 8.09, $p<0.05, \eta_{\mathrm{p}}{ }^{2}=0.37$ ) between QT4 and ST4. Subsequent separate ANOVAs for each level of Region between QT4 and ST4 showed a significant main effect of Intonation at the central $(F(1$, $\left.14)=4.66, p<0.05, \eta_{\mathrm{p}}{ }^{2}=0.25\right)$ and posterior sites $(F(1,14)=12.31$, $p<0.01, \eta_{\mathrm{p}}{ }^{2}=0.47$ ), with QT4 eliciting more positivity than ST4 at these regions. Despite the statistical insignificance $(p>0.05)$, it is worth emphasizing that the amplitude difference between QT4 and ST4 was more prominent at the posterior sites than at the central sites. At the frontal sites, however, no effect of Intonation was found $(p>0.05)$.

In sum, the results of ANOVAs did not reveal any effect for QT2 versus ST2. In contrast, an ERP effect was observed for QT4 versus ST4. The ERP effect took place in different time windows for the midline electrodes and the lateral electrodes, with a central-posterior distribution from 250 to $400 \mathrm{~ms}$ for the midline electrodes and a central-posterior distribution from 250 to $450 \mathrm{~ms}$ for the lateral electrodes. Through visual inspection of the waveforms, we identified a positive-going waveform peaking at about $300 \mathrm{~ms}$ after the onset of the critical word in the QT4 condition versus the ST4 condition in both the midline electrodes and the lateral electrodes. Taking together the polarity and the topographical distribution of the effect, we conclude that a P300 effect was found for QT4 versus ST4, whereas no effect was present for QT2 versus ST2.

\section{General discussion}

The present study investigated the online processing of tone and intonation in Mandarin at the attentive stage. We examined the behavioral and electrophysiological responses of native Mandarin listeners to Mandarin sentences, which contrast in final tones (Tone 2 or Tone4) and intonations (Question or Statement). The context of these sentences was manipulated to be semantically neutral. Our behavioral results showed that while the identification of tone was not hindered by intonation, the identification of intonation was greatly deteriorated by tone. In the Tone 4 conditions, question intonation was rather difficult to be correctly identified, whereas identification of statement intonation almost showed no difficulty at all. In the Tone 2 conditions, question intonation was still difficult to identify, while identification of statement intonation also tended to be problematic. Regarding ERP results, we found a clear P300 effect for questions ending with Tone 4 relative to statements ending with Tone4. No ERP difference was found between questions ending with Tone 2 and statements ending with Tone2.

According to previous studies, P300 reflects neurophysiological mechanisms of decision-making and categorical processing (Azizian et al., 2006; Courchesne et al., 1977; Kotchoubey and Lang,
2001; Kutas et al., 1977). When the categorization becomes more difficult, P300 amplitudes become smaller (Polich, 2007; Verleger et al., 1985). The P300 requires attention. Previous studies also suggested that P300 amplitude is larger when participants devoted more effort to a task (Johnson, 1984, 1986; Isreal et al., 1980). Intuitively, one may expect that an increase in task difficulty leads to investment of more effort and should thus elicit large P3 amplitude (Kok, 2001). However, the P300 amplitude decreases when tasks become perceptually or cognitively more demanding (Luck, 2005). Therefore, our ERP results above suggest that at the attentive processing stage, the question-statement contrast in Tone 4 conditions is easier to categorize, whereas categorization of the question-statement contrast in the Tone 2 conditions is much more demanding for Mandarin native listeners. These results are highly consistent with the MMN studies examining the online processing of tone and intonation in Mandarin at the pre-attentive stage. In those two studies (Ren et al., 2009, 2013), listeners are able to perceive the difference between question and statement intonation when the intonation associates with a Tone4 (reflected in an MMN effect), but they cannot make a distinction between question and statement intonation when the intonation associates with a Tone2 (reflected in no MMN). The MMN studies used one-syllable sentences, while our study extended the length of the utterances from one syllable to five syllables. Results in our study seem to confirm that the online processing patterns of tone and intonation in Mandarin maintain from the pre-attentive stage to the attentive stage over a longer utterance.

Though consensus have been reached that question intonation can be distinguished online from statement intonation when the sentences end with Tone4, one may question why the P300 effect is elicited in questions ending with Tone 4 compared to statements ending with Tone4, rather than vice versa. In the above MMN studies (Ren et al., 2009, 2013) and many other P300 studies, a target and a non-target are preset in the design. Very often participants just respond to the target stimuli. The corresponding ERP effect is therefore detected in the target category relative to the non-target category. In our study, no target category is set in advance, and neither is the case that participants responded only to one category. With equal probability of the two intonation types for Tone4, we also did not expect any bias due to selective tuning (Hillyard et al., 1973; Rohrbaugh et al., 1974). All in all, the two conditions hold equal possibility of eliciting P300 effect in principle. So what makes question ending with Tone4 outperform its statement counterpart? Evidence from the resource framework has shown that P300 amplitude is sensitive to the allocation of resources. P300 amplitude is larger when participants devoted more effort to a task (Johnson, 1984, 1986; Isreal et al., 1980). The advantage of questions endings with Tone 4 over statements ending with Tone 4 in the present study, therefore, seems to suggest that participants devote more processing effort to the former compared to the latter. As mentioned earlier, P300 is typically elicited in the target condition relative to the non-target condition. Azizian et al. (2006) proposed that equally probable stimuli that were easily evaluated as non-target required less mental work for discrimination and produced no P300-like components. From this line of reasoning, with a final Tone4, question intonation seems to be evaluated as possessing target-like properties, whereas statement intonation is evaluated as possessing non-target-like properties. Interestingly, this assumption happens to coincide with the view that statement intonation is a default intonation type and question intonation is a marked intonation type (Peters and Pfitzinger, 2008; Yuan, 2011). It appears that as a default intonation type, statement intonation occupies less mental attention or effort 
to be identified, leading to attenuated or even diminished P300 amplitude. In contrast, question intonation requires extra mental attention in order to be identified, resulting in increased P300 amplitude.

Interestingly, a comparison of our ERP results with the behavioral results revealed a discrepancy. In sentences ending with Tone4, question and statement contrast can be perceived electrophysiologically (reflected in P300). Behaviorally, listeners still had difficulty identifying question intonation (reflected in an identification rate of $68 \%$, which was only marginally significantly $(p<0.05)$ above chance level, i.e., 50\%) from statement intonation. This discrepancy could possibly be ascribed to the different processing that the neural responses and the behavioral responses reflect. In our study, the recorded EEG was time-locked to the onset of the critical syllable, whereas the behavioral responses were collected one second after the presentation of the stimuli. With such setup, one would not expect an isomorphic mapping between the neural responses and the behavioral responses, as P300 reflects cognitive processing restricted to a limited set of scalp electrodes within a limited temporal window, whereas the behavioral responses reflect whole brain processing. ${ }^{2}$

Despite the discrepancy between the ERP results and the behavioral results for Tone 4 conditions, the behavioral results in the present study are not uninterpretable. Our results showed that tone identity was seldom affected by intonation, while intonation identification was greatly affected by tone. Specifically, question intonation had a much lower identification rate than statement intonation regardless of final tone identities. For statement intonation identification, statements ending with Tone4 showed a significantly higher identification rate (99.3\%) than statements ending with Tone2 (91.3\%). These results are in line with previous studies (Xu and Mok, 2012; Yuan, 2011). However, our results concerning question intonation identification were different from what was reported in Yuan (2011). Yuan (2011) found that questions ending with Tone 4 were easier to identify than questions ending with Tone2. In our study, no statistically significant difference was found between questions ending with Tone4 (68\%) and questions ending with Tone2 (64\%). A closer comparison between these studies led us to infer that neutral semantic context might pose great difficulty to question intonation identification in questions ending with Tone4. In another study (Liu et al., 2016), we examined context effects on question intonation identification in the questions ending with Tone 2 condition and the questions ending with Tone 4 condition in two behavioral experiments. One experiment embedded the target syllables in a neutral semantic sentence context; the other embedded the target syllables in a highly constraining semantic sentence context. What we found is that in the neutral semantic context, questions ending with Tone 4 was not easier than questions ending with Tone2 for question intonation identification. However, in the highly constraining semantic context, question intonation was much better identified in questions ending with Tone 4 than in those ending with Tone2, as was in Xu and Mok (2012) and Yuan (2011). Even more interesting is that in low-pass filtered speech context, Xu and Mok (2014) found that questions ending with Tone2 had a higher accuracy rate than questions ending with Tone4. From the hierarchy of question intonation identification in Tone 2 and Tone 4 conditions in the above studies, it seems that context plays a role in question intonation identification. The stronger the linguistic context is (highly constraining semantic context $>$ neutral semantic context $>$ low-pass filtered context), the better the identification of question intonation in questions ending with Tone4.

\footnotetext{
${ }^{2}$ This point is put forward by one of our anonymous reviewers. We sincerely thank the reviewer for the constructive comments.
}

The opposing pattern was observed for questions ending with Tone2, with better identification of question intonation for weaker linguistic context. We infer that with less semantic information, frequency code (Ohala, 1983), high or rising pitch to mark questions, and low or falling to mark statements are more likely to be applied to intonation identification, resulting in relatively better identification of questions ending with Tone2. However, under no circumstance could listeners disentangle question intonation from Tone2 easily.

Semantic contexts affect question intonation perception. Speech contexts, however, impact question intonation production. Acoustic analyses in Yuan (2006) revealed that question intonation was realized as higher F0 at the end and steeper F0 slope of the final Tone2 than statement intonation in sentences ending with Tone2, and as higher F0 at the end of the final Tone 4 than statement intonation in sentences ending with Tone4. Our acoustic results are in agreement with Yuan's results for Tone2, but not for Tone4. We discovered not only a higher F0 at the end in questions than in statements as in Yuan (2006), but also a distinctively higher F0 at the initial contour of the final Tone 4 for questions ending with Tone4 in our data. These different acoustic realizations between Yuan (2006) and our study might result from different coarticulation patterns by the preceding tone contexts. In Yuan's speech materials, the target tone was preceded by a low tone. Tonal coarticulation causes F0 lowering at the initial part of the falling contour of Tone4. Question intonation thus has to be realized as rising in F0 at the end. In comparison, the target tone was preceded by high-level tones in our speech materials. Tonal coarticulation led to a rising in the initial F0 and made the high feature of Tone 4 more prominent. Meanwhile, F0 at the end of final Tone4 maintained its rising trend in question intonation.

Finally, it is interesting to compare the present study with the one conducted in Cantonese (Kung et al., 2014). Both studies investigated the online processing of tone and intonation under neutral semantic context. Using similar designs, the present study discovered a P300 effect for questions ending with Tone4 relative to statements ending with Tone4, while Kung et al. (2014) observed a P600 effect for low tone in questions relative to low tone in statements. The P300 effect in Mandarin reflected the ease with which question and statement intonation can be distinguished in sentences with a final Tone4. However, the P600 effect in Cantonese revealed the strong conflicts and processing difficulties when intonation-induced F0 changes lead to the activation of two competing lexical representations. The two ERP components revealed different realizations of interaction of tone and intonation in Mandarin and Cantonese. In Mandarin, tone identity maintains with the presence of intonation. Intonation identification is, however, greatly susceptible to the final tone identity. Question intonation is easier to be distinguished from statement intonation if the sentences bear a final Tone4, whereas the difference between intonation types is harder to perceive if the sentences bear a final Tone2. In Cantonese, tone identity is heavily distorted by intonation. The F0 contour of the low tones obtain a rising tail in questions, making it resemble the F0 contour of the mid-rising tone and therefore, causing processing difficulties in lexical identification.

\section{Conclusion}

To conclude, the present study provides online evidence that listeners can distinguish between question intonation and statement intonation when the intonation is associated with a final Tone4, but fail to do so when the intonation is associated with a final Tone 2 at the attentive stage of processing. This study extended the sentence scope from one syllable to several syllables, 
expanded ERP evidence from the pre-attentive stage of processing to the attentive stage of processing, and revealed different realizations of interaction of tone and intonation in Mandarin and Cantonese.

\section{Acknowledgments}

This research was supported by the China Scholarship Council for CSC scholarship to Min Liu and the European Research Council for the ERC Starting Grant (206198) to Yiya Chen. We thank Qingfang Zhang for making available the EEG equipment.

\section{Appendix A}

See appendix Tables.

Table A1

Time course analyses for the Midline Electrodes. F-values are reported for the main effects of T (Tone), I (Intonation) and interactions of T (Tone), I (Intonation) with $\mathrm{R}$ (Region).

\begin{tabular}{lllllll}
\hline Time Window $(\mathrm{ms})$ & $\mathrm{T}$ & $\mathrm{I}$ & $\mathrm{T} \times \mathrm{I}$ & $\mathrm{T} \times \mathrm{R}$ & $\mathrm{I} \times \mathrm{R}$ & $\mathrm{T} \times \mathrm{I} \times \mathrm{R}$ \\
\hline $0-50$ & $8.87^{\mathrm{c} *}$ & 0.23 & 0.58 & 1.37 & 1.12 & 0.03 \\
$50-100$ & 0.00 & 1.13 & 0.00 & 0.66 & 1.44 & 1.71 \\
$100-150$ & 0.03 & 1.05 & 0.04 & 1.28 & $5.19^{\mathrm{c} *}$ & 0.49 \\
$150-200$ & 4.04 & 2.42 & 0.48 & 1.00 & 1.14 & 2.20 \\
$200-250$ & 0.63 & 3.93 & 0.42 & 1.56 & 3.13 & $5.71^{\mathrm{c} *}$ \\
$250-300$ & 3.39 & $8.33^{\mathrm{c} *}$ & 1.57 & 0.26 & 1.48 & $3.68^{\mathrm{c} *}$ \\
$300-350$ & 1.35 & $7.90^{\mathrm{c} *}$ & 2.13 & 1.22 & $4.49^{\mathrm{c} *}$ & 1.37 \\
$350-400$ & 0.43 & $5.53^{\mathrm{c} *}$ & 0.57 & 0.13 & 2.63 & $6.21^{\mathrm{c} *}$ \\
$400-450$ & 0.11 & 3.69 & 1.15 & 0.95 & 0.56 & 2.70 \\
$450-500$ & 0.03 & 2.05 & 1.59 & 0.00 & 1.40 & $2.48^{\mathrm{c} *}$ \\
$500-550$ & $9.19^{\mathrm{c} * * *}$ & $6.63^{\mathrm{c} *}$ & 2.26 & 0.66 & 1.09 & 1.83 \\
$550-600$ & 1.34 & 2.78 & 3.03 & 3.42 & 2.66 & $4.21^{\mathrm{c} *}$ \\
$600-650$ & 0.20 & $12.58^{\mathrm{c} * \mathrm{C} *}$ & 1.30 & 0.79 & 0.09 & 2.28 \\
$650-700$ & 0.97 & 3.33 & 0.61 & 1.59 & 3.43 & 0.79 \\
$700-750$ & 1.25 & $9.73^{\mathrm{c} * \mathrm{C} *}$ & 0.18 & 0.86 & 1.27 & 2.13 \\
$750-800$ & 0.62 & 0.25 & 0.71 & 0.07 & $5.17^{\mathrm{c} *}$ & 1.76 \\
\hline
\end{tabular}

c* $p<0.05$.

c*c* $p<0.01$.

\section{References}

Azizian, A., Freitas, A.L., Watson, T.D., Squires, N.K., 2006. Electrophysiological correlates of categorization: P300 amplitude as index of target similarity. Biol. Psychol. 71 (3), 278-288. http://dx.doi.org/10.1016/j.biopsycho.2005.05.002.

Bates, D., Maechler, M., Bolker, B., Walker, S., 2015. Fitting linear mixed-effects models using lme4. J. Stat. Softw. 67 (1), 1-48. http://dx.doi.org/10.18637/jss. v067.i01.

Boersma, P., Weenink, D., 2015. Praat: Doing Phonetics by Computer (Version 5.4.21) [Computer program]. Retrieved from: 〈http://www.praat.org/ $\rangle$.

Bogacz, R., Brown, E., Moehlis, J., D.Cohen, J., 2006. The physics of optimal decision making: a formal analysis of models of performance in two-alternative forcedchoice tasks. Psychol. Rev. 113 (4), 700-765.

Cao, J., 2004. Intonation structure of spoken Chinese: university and specificity, Rep. Phon. Res., 31-38.

Chao, Y.R., 1929. Beiping Yudiao de Yanjiu [On intonation in Beijing Mandarin]. In: Wu, Z., Zhao, X., (Eds.), Chao Yuen Ren's Linguistic Papers The Commerical Press, Beijing , pp. 253-271 (in Chinese).

Chao, Y.R., 1933. Tone and intonation in Chinese. Bull. Inst. Hist. Phiol. 4, 121-134.

Chen, H.-C., Vaid, J., Wu, J.-T., 2009. Homophone density and phonological frequency in Chinese word recognition. Lang. Cogn. Process. 24 (7-8), 967-982. http://dx.doi.org/10.1080/01690960902804515.

Connell, B.A., Hogan, J.T., Rozsypal, A.J., 1983. Experimental evidence of interaction between tone and intonation in Mandarin Chinese. J. Phon. 11 (4), 337-351.

Courchesne, E., Hillyard, S.A., Courchesne, R.Y., 1977. P3 waves to the discrimination of targets in homogeneous and heterogeneous stimulus sequences. Psychophysiology 14 (6), 590-597.

Cutler, A., Chen, H.-C., 1997. Lexical tone in Cantonese spoken-word processing. Percept. Psychophys. 59 (2), 165-179. http://dx.doi.org/10.3758/BF03211886.

Da, J., 2004. A corpus-based study of character and bigram frequencies in Chinese e-texts and its implications for Chinese language instruction. In: Zhang, P., Xie T., Xu, J., (Eds.), Proceedings of 4th International Conference on New Technologies in Teaching and Learning Chinese. The Tsinghua University Press, Beijing, pp. 501-511.

Fok-Chan, Y.-Y., 1974. A Perceptual Study of Tones in Cantonese. University of Hong Kong Press, Hong Kong.

Frenck-Mestre, C., Meunier, C., Espesser, R, Daffner, K., Holcomb, P., 2005. Perceiving nonnative vowels: the effect of context on perception as evidenced by event-related brain potentials. J. Speech Lang. Hear. Res. 48, 1496-1510.

Friederici, A.D., 2002. Towards a neural basis of auditory sentence processing. Trends Cogn. Sci. 6 (2), 78-84.

Fritz, J.B., Elhilali, M., David, S.V., Shamma, S.A., 2007. Auditory attention — focusing the searchlight on sound. Curr. Opin. Neurobiol. 17 (4), 437-455. http://dx.doi. org/10.1016/j.conb.2007.07.011.

Gandour, J., Ponglorpisit, S., Khunadorn, F., Dechongkit, S., Boongird, P., Boonklam, R., Potisuk, S., 1992. Lexical tones in Thai after unilateral brain damage. Brain Lang. 43 (2), 275-307. http://dx.doi.org/10.1016/0093-934X(92)90131-W.

Gårding, E., 1987. Speech act and tonal pattern in standard Chinese: constancy and variation. Phonetica 44 (1), 13-29.

Garellek, M., Keating, P., Esposito, C.M., Kreiman, J., 2013. Voice quality and tone identification in White Hmong. J. Acoust. Soc. Am. 133 (2), 1078-1089. http: //dx.doi.org/10.1121/1.4773259.

Gussenhoven, C., Chen, A., 2000. Universal and language-specific effects in the perception of question intonation. In: Proceedings of the 6th International Conference on Spoken Language Processing (ICSLP 2000). pp. 91-94.

Hillyard, S.A., Hink, R.F., Schwent, V.L., Picton, T.W., 1973. Electrical signs of selective attention in the human brain. Science 182, 177-180.

Table A2

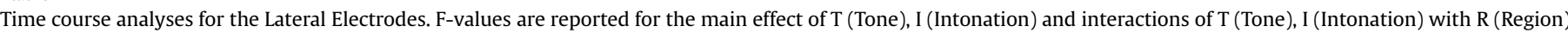
and $\mathrm{H}$ (Hemisphere).

\begin{tabular}{|c|c|c|c|c|c|c|c|c|c|c|c|c|}
\hline Time Window (ms) & $\mathrm{T}$ & I & $\mathrm{T} \times \mathrm{I}$ & $\mathrm{T} \times \mathrm{R}$ & $\mathrm{I} \times \mathrm{R}$ & $\mathrm{T} \times \mathrm{H}$ & $\mathrm{I} \times \mathrm{H}$ & $\mathrm{T} \times \mathrm{I} \times \mathrm{R}$ & $\mathrm{T} \times \mathrm{I} \times \mathrm{H}$ & $\mathrm{T} \times \mathrm{R} \times \mathrm{H}$ & $\mathrm{I} \times \mathrm{R} \times \mathrm{H}$ & $\mathrm{T} \times \mathrm{I} \times \mathrm{R} \times \mathrm{H}$ \\
\hline $0-50$ & $7.31^{\mathrm{c} *}$ & 0.11 & 0.47 & $4.15^{\mathrm{c*}}$ & 0.93 & 1.61 & 0.82 & 0.05 & 0.27 & 2.04 & 1.34 & 0.01 \\
\hline $50-100$ & 0.00 & 1.59 & 0.01 & 0.03 & 2.66 & 0.05 & 0.53 & 0.36 & 1.07 & $6.63^{\mathrm{C} * \mathrm{C} *}$ & 0.19 & $5.07^{\mathrm{c} *}$ \\
\hline $100-150$ & 0.00 & 1.74 & 0.13 & 0.56 & $6.98^{\mathrm{c} * \mathrm{c} *}$ & 0.67 & 0.63 & 0.29 & 0.04 & 0.11 & 2.18 & 0.21 \\
\hline 150-200 & 3.62 & 3.13 & 0.29 & 0.99 & 1.98 & 0.99 & $6.24^{\mathrm{C} *}$ & 0.37 & 0.05 & 3.08 & 0.73 & 1.90 \\
\hline $200-250$ & 0.49 & 4.29 & 0.39 & 1.45 & 3.91 & 0.11 & 0.87 & 1.80 & 1.02 & 0.34 & 0.92 & 0.68 \\
\hline $250-300$ & 3.51 & $8.57^{\mathrm{c} *}$ & 1.32 & 0.30 & 1.15 & 0.26 & $5.11^{\mathrm{c} *}$ & 0.76 & 0.22 & 1.19 & 1.50 & 2.39 \\
\hline $300-350$ & 1.31 & $8.70^{\mathrm{c} *}$ & 1.78 & 1.32 & $4.31^{\mathrm{C} *}$ & 0.39 & 0.00 & 0.26 & 0.02 & 0.60 & 0.80 & 0.55 \\
\hline $350-400$ & 0.62 & $7.52^{\mathrm{c*} *}$ & 0.63 & 0.04 & 3.74 & 1.83 & 0.50 & 3.24 & 0.00 & 2.19 & 0.42 & 0.98 \\
\hline $400-450$ & 0.15 & $4.63^{\mathrm{C} *}$ & 1.08 & 1.07 & 1.89 & 1.11 & 0.08 & 1.16 & 0.49 & 0.30 & 0.14 & 0.39 \\
\hline $450-500$ & 0.00 & 3.66 & 1.75 & 0.02 & $3.99^{\mathrm{C} *}$ & 1.24 & 0.08 & 0.86 & 0.50 & 2.55 & 0.59 & 2.05 \\
\hline $500-550$ & $7.41^{\mathrm{c} *}$ & $8.02^{\mathrm{C} *}$ & 2.21 & 0.54 & 1.96 & 0.59 & 0.42 & 0.24 & 0.17 & 0.03 & 0.11 & 0.18 \\
\hline $550-600$ & 1.18 & 3.98 & 3.36 & 2.10 & $5.66^{\mathrm{c*}}$ & 0.04 & 0.13 & 1.56 & 0.21 & 0.93 & 0.17 & 0.69 \\
\hline $600-650$ & 0.11 & $13.43^{\mathrm{c} *(*)}$ & 1.31 & 0.22 & 0.51 & 0.36 & 0.18 & 1.14 & 0.56 & 0.91 & 0.21 & 0.00 \\
\hline $650-700$ & 0.76 & 4.04 & 0.47 & 0.51 & $10.24^{\mathrm{c} * \mathrm{c} *}$ & 1.17 & $7.35^{\mathrm{c} *}$ & 0.23 & 0.03 & 1.05 & 0.12 & 0.24 \\
\hline $700-750$ & 1.25 & $11.37^{\mathrm{C} * \mathrm{C} *}$ & 0.24 & 0.46 & 1.73 & 1.69 & 0.04 & 1.37 & 0.15 & 0.94 & 1.13 & 0.25 \\
\hline $750-800$ & 0.83 & 0.53 & 0.69 & 0.03 & $8.53^{\mathrm{c} * \mathrm{C} *}$ & 1.98 & 2.81 & 0.43 & 0.25 & 1.25 & 0.51 & 1.70 \\
\hline
\end{tabular}

c* $p<0.05$.

c*** $p<0.01$. 
Ho, A.T., 1977. Intonation variation in a Mandarin sentence for three expressions: interrogative, exclamatory and declarative. Phonetica 34; , pp. 446-457, http:/ www.karger.com/DOI/10.1159/000259916.

Hu, M., 1987. Guanyu Beijinghua de Yudiao Wenti [On the Intonation of Beijing Mandarin]. The Commerical Press, Beijing (in Chinese).

Isel, F., Alter, K., Friederici, A.D., 2005. Influence of prosodic information on the processing of split particles: ERP evidence from spoken German. J. Cogn. Neurosci. 17 (1), 154-167.

Isreal, J.B., Chesney, G.L., Wickens, C.D., Donchin, E., 1980. P300 and tracking difficulty: evidence for multiple resources in dual-task performance. Psychophysiology 17 (3), 259-273. http://dx.doi.org/10.1111/j.1469-8986.1980.tb00146.x.

Johnson, R., 1984. P300: a model of the variables controlling its amplitude. Ann. N. Y. Acad. Sci. 425, 223-229. http://dx.doi.org/10.1111/j.1749-6632.1984.tb23538.

Johnson, R., 1986. A triarchic model of P300 amplitude. Psychophysiology 23 (4), 367-384. http://dx.doi.org/10.1111/j.1469-8986.1986.tb00649.x.

Johnson, R., Donchin, E., 1980. P300 and stimulus categorization: two plus one is not so different from one plus one. Psychophysiology 17 (2), 167-178.

Klein, D., Zatorre, R.J., Milner, B., Zhao, V., 2001. A cross-linguistic PET study of tone perception in Mandarin Chinese and english speakers. Neurolmage 13 (4), 646-653. http://dx.doi.org/10.1006/nimg.2000.0738.

Kok, A., 2001. On the utility of P3 amplitude as a measure of processing capacity. Psychophysiology 38 (3), 557-577. http://dx.doi.org/10.1017/ S0048577201990559.

Kotchoubey, B., Lang, S., 2001. Event-related potentials in an auditory semantic oddball task in humans. Neurosci. Lett. 310, 93-96.

Kratochvil, P., 1998. Intonation in Beijing Chinese. In: Hirst, D., Cristo, A.D. (Eds.), Intonation Systems: A Survey of Twenty Languages. Cambridge Universtiy Press, Cambridge, pp. 417-431.

Kung, C., Chwilla, D.J., Schriefers, H., 2014. The interaction of lexical tone, intonation and semantic context in on-line spoken word recognition: an ERP study on Cantonese Chinese. Neuropsychologia 53, 293-309. http://dx.doi.org/10.1016/j. neuropsychologia.2013.11.020.

Kutas, M., McCarthy, G., Donchin, E., 1977. Augmenting mental chronometry: the P300 as a measure of stimulus evaluation time. Science 197, 792-795.

Ladd, D.R., 2008. Intonational Phonology. Cambridge University Press, Cambridge.

Li, X., Chen, Y., Yang, Y., 2011. Immediate integration of different types of prosodic information during on-line spoken language comprehension: an ERP study. Brain Res. 1386, 139-152. http://dx.doi.org/10.1016/j.brainres.2011.02.051.

Liang, J., Van Heuven, V.J., 2007. Chinese tone and intonation perceived by L1 and 2 listeners. In: Gussenhoven, C., Riad, T. (Eds.), Tones and Tunes, Volume 2: Experimental Studies in Word and Sentence Prosody 12-2. Mouton de Gruyter, Berlin/New York, pp. 27-61.

Liu, F., Xu, Y., 2005. Parallel encoding of focus and interrogative meaning in Mandarin Intonation. Phonetica 62; , pp. 70-87 http://www.karger.com/DOI/10. $1159 / 000090090$.

Liu, M., Chen, Y., Schiller, N., 2016. Context effects on tone and intonation processing in Mandarin. Proc. Speech Prosody 2016, 1056-1060. http://dx.doi.org/ 10.21437/SpeechProsody.2016-217.

Luck, S.J., 2005. An Introduction to the Event-Related Potential Technique. MIT Press, Cambridge, MA.

Ma, J.K.-Y., Ciocca, V., Whitehill, T.L., 2006. Effect of intonation on Cantonese lexical tones. J. Acoust. Soc. Am. 120 (6), 3978-3987. http://dx.doi.org/10.1121/ 1.2363927.

Ma, J.K., Ciocca, V., Whitehill, T.L., 2011. The perception of intonation questions and statements in Cantonese. J. Acoust. Soc. Am. 129 (2), 1012-1023. http://dx.doi. org $/ 10.1121 / 1.3531840$

Näätänen, R., 2001. The perception of speech sounds by the human brain as reflected by the mismatch negativity (MMN) and its magnetic equivalent (MMNm). Psychophysiology 38 (1), 1-21.

Nieuwenhuis, S., Aston-Jones, G., Cohen, J.D., 2005. Decision making, the P3, and the locus coeruleus-norepinephrine system. Psychol. Bull. 131 (4), 510-532. http://dx.doi.org/10.1037/0033-2909.131.4.510.

Ohala, J.J., 1983. Cross-language use of pitch: an ethological view. Phonetica 40 1-18 http://www.karger.com/DOI/10.1159/000261678.

Patel, S.H., Azzam, P.N., 2005. Characterization of N200 and P300: selected studies of the event-related potential. Int. J. Med. Sci. 2 (4), 147-154 http://www.ncbi. nlm.nih.gov/pmc/articles/PMC1252727/.

Peng, S.-h, Chan, M.K.M., Tseng, C.-y, Huang, T., Lee, O.J., Beckman, M.E., 2005. Towards a Pan-Mandarin System for Prosodic Transcription. In: Jun, S.-A. (Ed.), Prosodic Typology: The Phonology of Intonation and Phrasing. Oxford University Press, Oxford, pp. 230-270.

Peters, B., Pfitzinger, H.R., 2008. Duration and F0 interval of utterancefinal intonation contours in the perception of German sentence modality. In: Proceedings of INTERSPEECH 2008. pp. 65-68.

Pfefferbaum, A. Ford, J., Johnson, R., Wenegrat, B., Kopells, B.S., 1983. Manipulation of P3 latency: speed vs. accuracy instructions. Electroencephalogr. Clin. Neurophysiol. 55, 188-197.

Polich, J., 2007. Updating P300: an integrative theory of P3a and P3b. Clin. Neurophysiol. 18 (10), 2128-2148. http://dx.doi.org/10.1016/j.clinph.2007.04.019.

Pulvermüller, F., Shtyrov, Y., 2006. Language outside the focus of attention: the mismatch negativity as a tool for studying higher cognitive processes. Prog. Neurobiol. 79 (1), 49-71. http://dx.doi.org/10.1016/j.pneurobio.2006.04.004.

R Core Team, 2015. R: A Language and Evironmetnt for Stastical Computing. R Foundation for Stastical Computing, Vienna, Austria http://www.R-project.org. Ren, G., Tang, Y., Li, X., Sui, X., 2013. Pre-attentive processing of Mandarin Tone and intonation: evidence from event-related potentials. In: Signorelli, F., Chirchiglia, D. (Eds.), Functional Brain Mapping and the Endeavor to Understand the Working Brain. InTech, Croatia, pp. 95-108.

Ren, G., Yang, Y., Li, X., 2009. Early cortical processing of linguistic pitch patterns as revealed by the mismatch negativity. Neuroscience 162 (1), 87-95. http://dx. doi.org/10.1016/j.neuroscience.2009.04.021.

Rohrbaugh, J., Donchin, E., Eriksen, C., 1974. Decision making and the P300 component of the cortical evoked response. Percept. Psychophys. 15, 368-374.

Salisbury, D.F., Rutherford, B., Shenton, M.E., McCarley, R.W., 2001. Button-pressing affects P300 amplitude and scalp topography. Clin. Neurophysiol.: Off. J. Int. Fed. Clin. Neurophysiol. 112 (9), 1676-1684. http://dx.doi.org/10.1016/S1388 2457(01)00607-1.

Schirmer, A., Tang, S.-L., Penney, T.B., Gunter, T.C., Chen, H.-C., 2005. Brain responses to segmentally and tonally induced semantic violations in Cantonese. J. Cognit. Neurosci. 17 (1), 1-12. http://dx.doi.org/10.1162/089892905288005.

Shen, J., 1985. Beijinghua Shengdiao de Yinyu he Yudiao [The Range of Tones and Intonaiton in Mandarin]. In: Lin, T., Wang, L. (Eds.), Experimental Analyses on Beijing Mandarin. Peking University Press, Beijing, pp. 73-125 (in Chinese).

Shen, X.S., 1989. The Prosody of Mandarin Chinese Vol. 118. University of California Press, Berkeley, Los Angeles and California.

Shi, P., 1980. Sizhong Juzi de Yudiao Bianhua [Intonaiton Variations in four Sentence Types]. Lang. Teach. Linguist. Stud. 2, 71-81 (in Chinese).

Shih, C., 2000. A declination model of Mandarin Chinese. In: Botinis, A. (Ed.), Intonation: Analysis, Modelling and Technology. Kluwer Academic Publishers, The Netherlands, pp. 243-268.

Smith, D.B.D., Donchin, E., Cohen, L., Starr, A., 1970. Auditory averaged evoked potentials in man during selective binaural listening. Electroencephalogr. Clin. Neurophysiol. 28 (2), 146-152. http://dx.doi.org/10.1016/0013-4694(70)90182-3.

Tseng, C.-y, Su, C.-y, 2014. From ripples to waves, tides and beyond. In: Huang, C.-T, J., Liu, F.-h (Eds.), Peaches and Plums. Institute of Linguistics, Academia Sinica, Taipei, Taiwan, pp. 257-278.

Van Lancker, D., Fromkin, V.A., 1973. Hemispheric specialization for pitch and "tone": evidence from Thai. J. Phon. 1, 101-109.

Verleger, R., Gasser, T., Möcks, J., 1985. Short term changes of event related potentials during concept learning. Biol. Psychol. 20 (1), 1-16. http://dx.doi.org/ 10.1016/0301-0511(85)90036-5.

Verleger, R., Jaśkowski, P., Wascher, E., 2005. Evidence for an integrative role of P3b in linking reaction to perception. J. Psychophysiol. 19 (3), 165-181. http://dx. doi.org/10.1027/0269-8803.19.3.165.

Wang, Y., Sereno, J.A., Jongman, A., Hirsch, J., 2003. fMRI evidence for cortical modification during learning of Mandarin lexical tone. J. Cogn. Neurosci. 15 (7), 1019-1027. http://dx.doi.org/10.1162/089892903770007407.

Wu, Z., 1982. Putonghua Yuju zhong de Shengdiao Bianhua [Tonal Changes in Mandarin Discouses]. Zhongguo Yuwen 171 (6), 439-449 (in Chinese).

Wu, Z., 1996. A new method of intonation analysis for Standard Chinese: frequency transposition processing of phrasal contours in a sentence. In: F.G. et al. (Eds.), Analysis, Perception and Processing of Spoken Language, Elsevier Science B.V., Amsterdam.

Xu, B., Mok, P., 2012. Cross-linguistic perception of intonation by Mandarin and Cantonese Listeners. Proc. Speech Prosody 2012, 99-102.

Xu, B., Mok, P., 2014. Cross-linguistic perception of Mandarin intonation. Proc. Speech Prosody 2014, 638-642.

$\mathrm{Xu}, \mathrm{Y}$, 2004. Separation of functional components of tone and intonation from observed F0 patterns. In: Fant, G., Fujisaki, H., Cao, J., Xu, Y., (Eds.), From Traditional Phonology to Modern Speech Processing: Festschrift for Professor Wu Zongji's 95th Birthday. Foreign Language Teaching and Research Press, Beijing, pp. 483-505.

Xu, Y., 2005. Speech melody as articulatorily implemented communicative functions. Speech Commun. 46, 220-251.

$\mathrm{Xu}, \mathrm{Y} ., 2009$. Timing and coordination in tone and intonation-an articulatoryfunctional perspective. Ling.: Int. Rev. Gen. Linguist. 119 (6), 906-927. http://dx. doi.org/10.1016/j.lingua.2007.09.015.

Xu, Y., Wang, Q.E., 2001. Pitch targets and their realization: evidence from Mandarin Chinese. Speech Commun. 33 (4), 319-337.

Ye, Y., Connine, C.M., 1999. Processing spoken Chinese: the role of tone information. Lang. Cogn. Process. 14 (5-6), 609-630. http://dx.doi.org/10.1080/ 016909699386202.

Yip, M., 2002. Tone. Cambridge University Press, Cambridge.

Yu, K.M., Lam, H.W., 2014. The role of creaky voice in Cantonese tonal perception. J. Acoust. Soc. Am. 136 (3), 1320-1333. http://dx.doi.org/10.1121/1.4887462.

Yuan, J., 2006. Mechanisms of question intonation in Mandarin. In: Huo, Q., Ma, B., Chng, E.-S., Li, H., (Eds.), Chinese Spoken Language Processing 5th International Symposium, Springer Berlin Heidelberg, Singapore. pp. 19-30.

Yuan, J., 2011. Perception of intonation in Mandarin Chinese. J. Acoust. Soc. Am. 130 (6), 4063-4069. http://dx.doi.org/10.1121/1.3651818. 